\title{
Collaboration or Collusion? The New Era of Commercial Online Resources for Students in the Digital Age: an Opinion Piece
}

\author{
Cristian Lieneck \\ Texas State University - San Marcos, clieneck@txstate.edu \\ Salvador Esparza \\ California State University, Northridge, salvador.esparza@csun.edu
}

Follow this and additional works at: https://nsuworks.nova.edu/ijahsp

Part of the Adult and Continuing Education Commons, Health and Medical Administration Commons, Higher Education and Teaching Commons, Online and Distance Education Commons, and the Other Teacher Education and Professional Development Commons

\section{Recommended Citation}

Lieneck C, Esparza S. Collaboration or Collusion? The New Era of Commercial Online Resources for Students in the Digital Age: an Opinion Piece. The Internet Journal of Allied Health Sciences and Practice. 2018 Jan 01;16(3), Article 7.

This Opinion Piece is brought to you for free and open access by the College of Health Care Sciences at NSUWorks. It has been accepted for inclusion in Internet Journal of Allied Health Sciences and Practice by an authorized editor of NSUWorks. For more information, please contact nsuworks@nova.edu. 


\title{
Collaboration or Collusion? The New Era of Commercial Online Resources for Students in the Digital Age: an Opinion Piece
}

\begin{abstract}
The purpose of this paper is to share online resources available to students at a global level, to include healthcare administration programs and any other course of study. While somewhat daunting in nature, this editorial offers faculty of healthcare administration (and other related programs of study) the opportunity to explore what course materials (of any format) may be posted to commercial external websites by current and/or previous students for ongoing collaboration among academic cohorts. Findings include an opportunity for students in any program, at any level, to post individual and/or copyrighted course materials on public, external websites, often with an underlying motivation of financial remuneration for their efforts. Best practices for identifying individual course resources posted externally to the course are provided, while a potential solution for more effective and productive collaboration within the course and the internal course online learning management system is offered.
\end{abstract}

\section{Author Bio(s)}

Cristian $\mathrm{H}$. Lieneck is an Associate Professor of Healthcare Administration in the School of Health Administration at Texas State University in San Marcos, Texas. His research interests include physician practice management and core competencies of healthcare administrators.

Salvador Esparza is an Associate Professor and Director of Health Administration at California State University-Northridge. He has consulted for major tertiary health care organizations throughout the country with particular emphasis on operations, organizational and leadership development. 


\title{
TIUAHSP
}

\section{The Internet Journal of Allied Health Sciences and Practice}

Dedicated to allied health professional practice and education

Vol. 16 No. 3 ISSN 1540-580X

\section{Collaboration or Collusion? The New Era of Commercial Online Resources for Students in the Digital Age: an Opinion Piece}

\author{
Cristian Lieneck ${ }^{1}$ \\ Salvador Esparza²
}

1. Texas State University, San Marcos

2. California State University, Northridge

United States

\begin{abstract}
The purpose of this opinion piece is to share online resources available to students at a global level to include healthcare administration programs and any other course of study. While somewhat daunting in nature, this opinion piece presents faculty of healthcare administration (and other related programs of study) the opportunity to explore which course materials (of any format) may be posted to commercial external Web sites by current and/or previous students for ongoing collaboration among academic cohorts. Findings include an opportunity for students in any program at any level to post individual and/or copyrighted course materials on public, external Web sites, often with an underlying motivation of financial remuneration for their efforts. Best practices for identifying individual course resources posted externally to the course are provided while a potential solution for more effective and productive collaboration within the course and the internal course online learning management system is offered.
\end{abstract}

Key Words: online student collaboration, online student collusion, commercial student resources 


\section{INTRODUCTION}

The impetus for this opinion piece began during the summer of 2016 by two faculty members discussing a Master's of Healthcare Administration (MHA) healthcare finance course that they both taught throughout the academic year yet never at the same time during any one semester. As usual, teaching methods and methods of evaluation in the course among other topics are all common discourse among faculty members who teach a similar course, especially within the same degree program. In the end, one stringent requirement of the senior faculty member who was designated as the primary instructor for the course was that the other junior faculty member teaching the course not release the textbook publisher's answer key/guide to the students, which was provided as an instructor-only resource for the required textbook in the course. Instead, the primary faculty member preferred for the students to first attempt all problems in the back of the textbook chapters, then approach the faculty member during scheduled office hours to access the textbook key and review with the instructor, only after demonstrating that they had properly attempted each problem for which they required assistance.

For several years, this process of maintaining a single, hard-copy of the textbook publisher's answer guide worked very well as a learning resource for both the instructors and students. Students understood their personal responsibility to attempt all problems, work together on finding the same answers, and then approach the faculty member with specific, well-planned questions and demonstration of their attempt at each problem. Then, during one summer semester of the course, it was observed that no students were approaching that semester's faculty member with any questions about the healthcare finance problems from the back of the textbook chapters. Initially, the faculty member teaching the course that summer believed it to possibly be personal or some other faculty-specific variable. It was later discovered that simply through an online investigation with various search engines, the MHA class members had obtained access to the textbook publisher's answer guide already and had taken an alternate approach to completing the required chapter problems for the course, which was against the faculty members' course expectations.

\section{USE OF EDUCATIONAL RESOURCES: COLLABORATION OR COLLUSION?}

Students today are approaching university-level studies differently than in the past. They study differently, learn differently, and utilize many other online and other technology resources to access information and concepts related to the course. ${ }^{1}$ Technology has deeply changed education in the following ways. ${ }^{2}$

- Increased access to education. Whether rural institutions, evening programs for working adults, and even deployed military, learning online is used for industry professionals to access course content $24 / 7$ at their leisure.

- Communication and collaboration enhancement. With increased access comes increased collaboration. Previously, such students would not access higher education due to personal/work conflicts. Now they are able to participate in online discussions, group projects, and other collaboratives that permit them to offer their unique perspective, which was previously absent.

- As is the primary thesis of this article, technology continues to change the roles of teachers and learners. Moving from the traditional classroom to the technology-infused learning environment (in-personal or $100 \%$ online), instructors must adapt to today's online and information-sharing classroom.

In an attempt to further understand the current student culture with regard to the utilization of external online resources for a current undergraduate marketing course, we quickly initiated an online course site poll to assess levels collaboration outside of the course resources available. The following results are from an undergraduate Health Services Marketing course taken during the students' senior year and administered online (Table 1).

Table 1. Ad Hoc In-Class Assessment of Undergraduate Student (Senior Class) Use of External Online/Digital Resources Beyond the Online Course Site

\begin{tabular}{|cl|c|c|}
\hline \multicolumn{1}{|c|}{ Question } & Yes (\%) & No (\%) \\
\hline 1. & $\begin{array}{l}\text { I use the online course site as the primary resource for course resources, information, } \\
\text { and communication. }\end{array}$ & $29(97 \%)$ & $1(3 \%)$ \\
\hline 2. & My primary study resources are in digital/electronic form, versus papernotes. & $11(37 \%)$ & $19(63 \%)$ \\
\hline $3 . \quad \begin{array}{l}\text { I use online/social media tools (outside of the online course site) to helpwith my } \\
\text { studies. }\end{array}$ & $20(67 \%)$ & $10(33 \%)$ \\
\hline
\end{tabular}

Note: $(n=30)$

A notable result involves question \#3 in which over two-thirds of the class $(n=30)$ mentioned that they utilized some kind of online resource outside of the course's available resources to assist with their studies. While this number may seem quite high, it was also determined that most of these students (97\%) only accessed these external resources as a secondary measure for assisting in their

(c) The Internet Journal of Allied Health Sciences and Practice, 2018 
learning processes as demonstrated by the finding in question \#1. While this finding was only ad hoc and the survey limited to a current undergraduate cohort, it does demonstrate the prevalence of the use of external online resources for a majority of the students in the course, which can be assumed to easily apply to other courses that are taken by these exact same students at the exact same time, which was a characteristic of the cohort model utilized by the Bachelor's Healthcare Administration (BHA) program.

In an attempt to provide examples both positive (effective) and negative (ineffective) use of online and/or technological resources in the classroom and learning process, we have outlined their personal experiences and viewpoints of such resources below:

\section{Effective Collaboration}

- (www.quizlet.com) Students can create and then quiz themselves over course vocabulary, concepts, etc. The site is productive for students only if conveyed content is valid/correct.

- (www.studyblue.com) Very similar functionality as (www.quizlet.com). Again, the content uploaded/posted to this external Web site is not validated by any faculty member and may be incorrect, therefore, potentially providing ongoing, false information to future students.

\section{Inappropriate Collusion}

- $\quad$ "Secret" Facebook group sites that are protected by private membership/invitation only. For instance, naming the group site "548643218568153" (or any other unique, random sequence of characters) versus "HA 3375 study group" makes the online resource virtually unidentifiable by anyone except those privately invited to join (unsearchable via Facebook search tool).

- $\quad$ Commercialized resource-sharing external Web sites that offer financial remuneration to students whose uploaded resources are accessed the most by other students paying a membership to access the site and unlock individual resources (for more information, visit https://www.coursehero.com/earn-money/ and click on "watch our marketplace video").

- Posted $\mathrm{MP}_{3}$ (audio) or $\mathrm{MP}_{4}$ (video) files (student upload) to external Web sites that seem to be recorded faculty lectures/presentations. It was assumed these were unauthorized or unofficial content uploads/postings due to the very poor quality of the resource.

It should also be noted that conversations regarding these external Web sites with various students led to a follow-on discussion of whether or not specific faculty members post PowerPoint slides on the internal course Web site for students. While the decision to provide students with the lecture slides as an educational resource is solely the decision of the faculty member, one student (to remain anonymous) specifically mentioned that he/she would rather the faculty not post the PowerPoint slides so that when/if he/she were able to access them and post/upload to an external Web site, the slides would be more in demand and receive greater financial remuneration as a result. Faculty members are urged to make their own decision as to which materials are considered effective and collaborative external online resources as well as those that are tailored more towards inappropriate collusion.

\section{INVESTIGATION RESULTS}

Beginning with simple www.google.com searches, the faculty members identified online resources that were not simply pedagogical in nature but also those that are now known to be classified under the Commercial Notetaking Policy at the institution. ${ }^{3}$ After some time pursuing various sites offering access to educational resources by program and by course, it was determined that collaboration was not the primary intent of these online Web sites, especially those that required not only fees for students to access the resources but also offer financial remuneration for students whose resources are accessed more frequently. Appendix 1 has several of these Web sites identified in this study.

\section{Ineffective Collaboration: Repetition Versus Learning}

As for the healthcare finance course, a very interesting finding needs to be addressed. For both the midterm and final exam in the summer semester course, a significant number of the students (over $50 \%$ ) missed the same basic finance, short answer question on both exams. This situation was concerning to the faculty member teaching the class as it had been addressed several times during the course, including an in-class review of the midterm exam and missed items. However, it was not only missed on the final exam by many students, but they had all written the exact same incorrect answer (almost word-for-word). The course instructor later identified an uploaded resource under the course number on an external Web site. Within this study guide (detailed, typed course notes uploaded by a previous healthcare finance student from 2 semesters ago), there were many incorrect definitions, misguided concepts, and also the same incorrect short-answer that many of the summer healthcare finance students continued to miss throughout the most recent course. 


\section{Recommended External Web Site Review Process for Faculty}

At this point, one may be wondering, what is possibly out there in public view for the courses that I teach? Or, what about a course at your current (or previous) institution that you have taught in the past? Based on the experiences of the healthcare finance faculty member reviewing external Web sites for his course answer guide and other unknown course resources available to the general public, the following review process is recommended for any faculty member with similar concerns:

1. Go to www.coursehero.com (or insert any other Web site from Appendix 1 here).

2. Start big, and then drill down to the course or individual faculty member level. This review can be done by searching for the institution first, then the program of study, then the course identifier (either course name, course prefix and number, or possibly even the instructor's last name).

3. Continue to drill down until the individual document-upload level is reached to determine which online resources have been loaded on the site for others to access. While somewhat vague, this process is highly flexible and may vary based upon current day online Web site search engine parameters and algorithms.

\section{Best Practices Identified for Finding Course Materials Posted Publicly}

While this process may seem quite basic, we have identified some best practices to determine which (if any) individual course resources have been posted online for any instructor's course. Many hours were spent reviewing various sites that were located using many different methods, which can become very time consuming and unproductive. Table 2 below presents those actions that were shown to be most beneficial (and less time consuming) during this investigation to assist other faculty members in identifying if/which resources from their courses are posted in the public domain, unfamiliar to them.

Table 2. Best Practices in Identifying Course Resources Posted to External Web Sites

\begin{tabular}{|c|l|}
\hline Search tip & \multicolumn{1}{c|}{ Reasoning } \\
\hline 1 & $\begin{array}{l}\text { Start large. Begin with www.google.com and your course prefix and course number only. Next, add your last } \\
\text { name to these items in the search bar. Be sure to not only review the first page of search results because many } \\
\text { interesting findings will appear on other pages besides just the first page, which will often identify the Web sites } \\
\text { to visit and further investigate. }\end{array}$ \\
\hline 2 & $\begin{array}{l}\text { Use specific, evergreen course identifiers. Students are searching for longevity of their posted resources, } \\
\text { especially for those Web sites that pay for their postings that are accessed the most by other paying consumers } \\
\text { (students), even beyond the original poster's graduation from the program. Therefore, stick to the course prefix } \\
\text { and course number as this method of labeling the course-level information is the shortest length of characters } \\
\text { and not likely to change over time. }\end{array}$ \\
\hline 3 & $\begin{array}{l}\text { Review all documents uploaded under the department/program's section of uploaded materials. Often, students } \\
\text { will inadvertently upload something from your course to the incorrect course number, yet it will be correctly } \\
\text { placed under the department or program section of the Web site. }\end{array}$ \\
\hline 4 & $\begin{array}{l}\text { Just because it is blurred (or halfway blurred) in an attempt to entice other students to pay for full access of the } \\
\text { posted document/material, as the course instructor, it is often quite easy to determine which material is posted } \\
\text { and partially blurred because the instructor is either the original owner of the material or knows his/her course } \\
\text { materials instinctively. }\end{array}$ \\
\hline 5 & $\begin{array}{l}\text { You will most likely find many course-level links and posted online resources to other faculty members' materials } \\
\text { or uploaded resources. Often, you can simply copy/paste the long hyperlink on that current page in which you } \\
\text { found their materials and email it to them. This link should take them directly to the same page you were looking } \\
\text { at with their course site/materials posted. These links are often not password-protected (you do not have to pay } \\
\text { money to see the available material). }\end{array}$ \\
\hline
\end{tabular}

As external online resources for students continue to develop, these best practice search methods may need to be adjusted to remain effective. Regardless, as stated in the blinded, institutional policy, the policing of external online resources for students can be quite 
time consuming and costly for any individual faculty member, so an ongoing effort to combat such external postings by students may not be the best approach to addressing the potential collusion occurring for any one course (for this reason, an interim solution is offered at the end of this article).

\section{HIGHER LEVEL ISSUES Honor Code Violations}

Faculty members should be privy to their specific educational institution's policy for students' use of online shared resources and faculty expectations to enforce any such policy. At Texas State University, a policy exists that specifically addresses how commercial notetaking Web sites and sharing of resources in a manner that demonstrates collusion is in direct violation of the institution's Honor Code. ${ }^{4}$ Actions within the Honor Code that apply to this paper include collaboration/collusion and facilitating academic dishonesty. Instances in which these violations apply during the current investigation of external online resources include (but certainly not limited to) the following observations:

- $\quad$ Reproduced (student memorized) exam questions (or entire exams) posted online.

- Online course site screenshots (students using the CTRL + PRINT SCREEN function) to post an internal/online course site quiz or other evaluation question.

- $\quad$ Submitted written papers on common course topics for other students to view/access.

\section{Copyright Infringement}

During the online search for the healthcare finance textbook publisher's answer guide, many other course resources were identified (including those outside of the healthcare finance course) that were created independently by the healthcare finance course instructor in an attempt to assist in the learning process. These included custom-made PowerPoint presentations/slides, videos of the instructor discussing specific concepts either during lecture or from his desk, and custom-made homework questions and answer guides. All of these items were created by the healthcare finance course instructors to support the curriculum and the student learning process. While offered to the students via the institution's online learning management system during specific sections of the course each semester it is taught, it was surprising to see these items posted on a public, external Web site not associated with the institution.

Many of the external Web sites that allow for (or encourage) students to post course-level resources have the opportunity for copyright infringement reporting via their Web site pursuant to the Section 512(c)(3) of the Digital Millennium Copyright Act. ${ }^{5}$ However, this process of notification to the external Web sites is not the same, and each external Web site has its own method of informing them of uploaded documents etc. that should not be publicly shared online. In the process, the person who uploaded each file could file a counter notice to rebut the copyright infringement claim (in order to be notified of the infringement claim via the external Web site's reporting process). It should be mentioned that for the custom-made items mentioned above, separate notifications were to be submitted to www.coursehero.com via its Web site, and all files were removed from the site the same day as the notification. The healthcare finance textbook publisher (original author) was notified about the study guide posted to the external Web site.

\section{Professional Ethics as Healthcare Administration Students}

Setting true, valid online pedagogy methods aside, the most important issue in this entire study is the concern of students (graduate, undergraduate, healthcare administration, or any other major) participating in commercial and free course material sharing at a global (online) level. As both current and future healthcare management professionals, they are expected to act in accordance with not only their current institution's honor code expectations but also a code of ethics as required by their profession, such as the American College of Healthcare Executives' Code of Ethics. ${ }^{6}$

By not following the instructor's pedagogical method in the course, the students' goals were assumed to simply obtain the correct answer at any cost regardless if the underlying concept supporting the financial equations were understood. In these dynamic times of reform, change, and uncertainty, our industry requires healthcare administrators who have learned something from their studies, not simply someone who has passed a course by gaining access to the answer guide and/or others' resources. Our industry deserves better.

\section{INTERIM SOLUTION AND CONCLUSION}

Based on the volume of material discovered at the per course level for both the MHA and BHA programs and the proliferation of materials for courses of faculty colleagues identified at neighboring institutions, the findings from the summer healthcare finance course and this study were presented at a faculty meeting, and the search tips were provided for all faculty members to investigate on their own. ${ }^{7}$ Even before the presentation had concluded, faculty members were pulling up these external Web sites on their laptops/smartphones and finding their course materials and shared online resources for their specific course sections in amazement. 
While not exactly an uplifting topic to report on in the field of healthcare administration education, there is always an opportunity to make lemonade from lemons, which is the impetus that continues to keep us intrigued in the art of teaching at the university level. For instance, Hopwood et al provided an exceptional case study report on this very same issue in another health profession program as well as the opportunity to transform the deemed inappropriate use of external online resources into a learning process for the students. ${ }^{8}$ In this same vein, an effort to present an interim solution was offered by us to healthcare administration faculty in an attempt to further embrace the use of increased sharing and collaboration within and between course cohorts in an ethical, controlled, and appropriate manner. We teach both in-person and online courses at various institutions and are well aware of the online resources available to students both within any learning management system as well as external Web site resources. Therefore, all our course sites now have an open-access folder for students to utilize and post resources to share among each other. As discussed in Appendix 2, this folder is copied between semesters by the faculty, so the students' contributions towards a body of knowledge will continue to grow upon prior cohort contributions. While this folder is not constantly monitored by the faculty (and has instructions that notate the lack of monitoring specifically), it was created in an attempt to keep all course resources in-house and within the true course site versus some external Web site that has commercialized notetaking and resource sharing at the students' expense.

In the end, times are changing. Students do not take notes the same way as their faculty members did when they were students. Students do not study the same way as their faculty members once did. And in today's online and information sharing world, it has been validated that students do share much more than their faculty members ever did as students (including their grades, notes, and anything else to do with their current and previous course experiences). As faculty, adaptation to the learning environment and the learners within is key. However, even with all of the online resources available to students, test banks published for all to see, answer guides available for homework assistance instead of the course instructor, etc., one best practice for faculty members to retain control of the course content and valid methods of evaluation remains the ability to change the method of evaluation frequently. ${ }^{9}$ In other words, if faculty is issuing the same multiple-choice questions each semester, the same short-answer, essay questions, etc., it can easily be assumed that these items are already in the hands of the students before the course has even started as demonstrated by our findings. To conclude, just remember that if it is available within your course lecture, online course site, or any other class resource at any level (digital resource or otherwise), assume that it is already out there in the public domain.

\section{REFERENCES}

1. Black A, Gen Y. Who they are and how they learn. Educational Horizons. 2010;(2):92.

2. How Has Technology Changed Education? Purdue.edu. Available at: http://online.purdue.edu/ldt/learning-designtechnology/resources/how-has-technology- changed-education. Accessed January 22, 2018.

3. Texas State University Commercial Notetaking Policy. Available at: www.txstate.edu. Accessed November 4, 2017.

4. Texas State University Honor Code Policy. Texas State University UPPS No. 07.10.01, Issue No. 8. www.txstate.edu. Available at: http://policies.txstate.edu/university-policies/07-10- 01.html. Accessed November 4, 2017.

5. Executive Summary of the Digital Millennium Copyright Act. Section 104 Report. Copyright.gov. Available at: https://www.copyright.gov/reports/studies/dmca/dmca_executive.html. Accessed January 22, 2018.

6. ACHE Code of Ethics. ACHE.org. Available at: https://www.ache.org/abt_ache/code.cfm. Updated November 14, 2016. Accessed December 15, 2017.

7. Lieneck C. Cheating in College? A lecturette prepared for the Texas State University Health Administration Program. August $15,2016$.

8. Hopwood J, Scott V, Ferguson P. A case study transforming suspected academic misconduct among undergraduate health professions majors into ethical program policy and practice. J College Character. 2011;12(2).

9. Johnston H, Education Partnerships I. Cheating. Research Brief. June 18, 2007; Available from: ERIC, Ipswich, MA. Accessed November 4, 2017.

10. Academic Integrity Tips: Preventing and Responding to Cheating. www.csun.edu. Faculty Development email received on November 7, 2016. 
Appendix 1. List of External Online Web sites that Facilitate Student Resource Sharing

www.coursehero.com

www.koofers.com

www.papercamp.com

www.studymode.com

www.antiessay.com

www.quizlet.com

www.prestoexperts.com

www.studyblue.com

www.getstudyroom.com

Notes: 1) This list is not all-inclusive, and each Web site contains varying levels of resource-sharing at any one point in time. 2) Several of these Web site resources were provided by a Faculty Development email from California State University Northridge. ${ }^{10}$ 


\section{Appendix 2. Student-Generated Resource Folder for Course Content}

School of Health Administration department students,

It has come to my attention that many students (even beyond the School of Health Administration) are utilizing various non-Texas State University social media and similarly related external websites to assist with their studies. Often, these sites promote collaboration beyond the classroom, limiting the proper use of internal course resources, such as our Course Site.

That said, I've decided to create a "Student-Generated Resources Folder" within our course site. This folder has open permissions for any current student in the course to upload, edit, and even delete any resource they would like to share with their fellow colleagues.

What will make this site valuable (in my professional opinion) is the ongoing, evergreen characteristic of the site - I will continue to copy all remaining materials in the Student- Generated Resource Folder from one semester to the next, with an assumption that it will only grow in size, therefore increasing the body of knowledge, study materials, and other student notes available for future students enrolled in the course.

Please feel free to utilize this folder as you wish - I will not be checking/monitoring the folder frequently, but will be sure to enforce proper "netiquette" and appropriateness of potential materials. I will also not guarantee that everything in this folder is $100 \%$ correct again, this is your resource to assist in the course, but my lectures, materials, and other sections of the course site are formal/official throughout the duration of the course.

So, have at it! Upload any materials here you would like to share with your colleagues and future cohorts. Feel free to delete anything you add at any time.

Let's make the course site our \#1 tool for online collaboration, and not some third-party website that has limited capabilities.

Thanks, Dr. Lieneck 